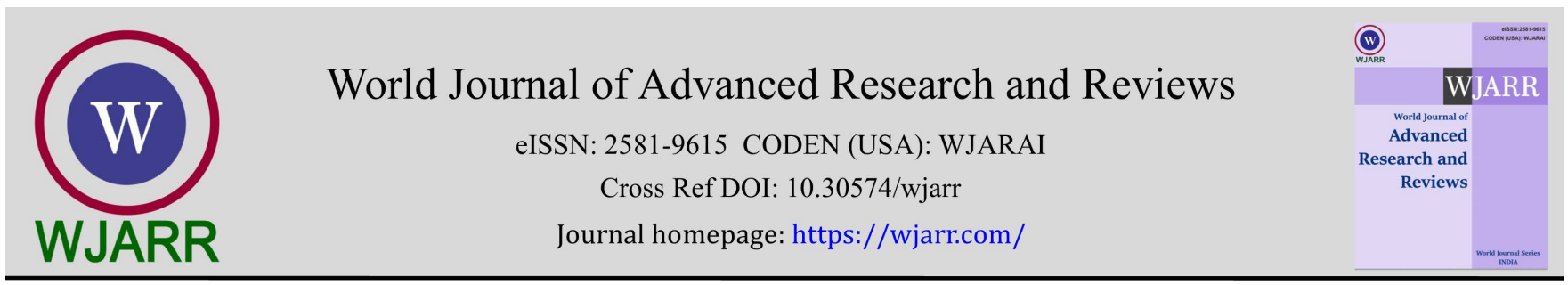

(RESEARCH ARTICLE)

Check for updates

\title{
Comparative assessment of the pulping potentials of soda and mea processes for the development of paper-pulp from sugarcane bagasse
}

\author{
Henry Okwudili Chibudike ${ }^{1, *}$, Nelly Acha Ndukwe ${ }^{2}$, Eunice Chinedum Chibudike ${ }^{3}$, Nkemdilim Ifeanyi Obi 4 \\ and Olubamike Adetutu Adeyoju ${ }^{5}$ \\ ${ }^{1}$ Chemical, Fiber and Environmental Technology Department, Federal Institute of Industrial Research, Oshodi, F.I.I.R.O., \\ Lagos-Nigeria. \\ 2 Department of Chemical Sciences, College of Basic \& Applied Sciences, Mountain Top University, Magoki, Ogun State, \\ Lagos-Nigeria. \\ 3 Planning, Technology Transfer and Information Management, Federal Institute of Industrial Research, Oshodi, F.I.I.R.O., \\ Lagos-Nigeria. \\ ${ }^{4}$ National Oil Spill Detection and Response Agency (NOSDRA), Abuja-Nigeria. \\ ${ }_{5}^{5}$ Production, Analytical and Laboratory Management, Federal Institute of Industrial Research, Oshodi, F.I.I.R.O., Lagos- \\ Nigeria.
}

World Journal of Advanced Research and Reviews, 2021, 12(01), 230-242

Publication history: Received on 27 August 2021; revised on 30 September 2021; accepted on 02 October 2021

Article DOI: https://doi.org/10.30574/wjarr.2021.12.1.0497

\begin{abstract}
Pulping trials were carried out using MEA and the soda process comparing their pulping potentials. The operating conditions such as the concentration of the cooking liquor $(50 \%, 75 \%, 100 \%)$ for MEA and $(10 \%, 15 \%, 20 \%)$ for $\mathrm{NaOH}$, the maximum cooking temperature $\left(150^{\circ} \mathrm{C}, 160^{\circ} \mathrm{C}, 170^{\circ} \mathrm{C}\right)$ and cooking time $(60,90,120$ minutes $)$ for both processes were investigated systematically to establish optimal pulping conditions. The agro-biomass used in this investigation is Sugarcane Bagasse viewed as alternative raw material for pulp and paper production. The lignin content of Bagasse (19.5\%) was low; indicating that Bagasse should be easier to pulp. The optimum cooking conditions (independent variables) for MEA pulping were $75 \%$ MEA concentration, $150^{\circ} \mathrm{C}$ cooking temperature and 90 minutes cooking time. Excel 2013 was used to analyze the effect of independent variables on yield of bagasse pulp and properties of furnished paper from MEA process in comparison with the Soda process which include tear index, tensile index, burst index and folding endurance with errors less than $15 \%$ in all cases. The Kappa number range (12.7-16.9), viscosity (270-870 ml/g) and brightness (62.1-93.2\%) of bagasse pulp are appropriate for high-brightness printing and writing papers. The physical properties of furnished paper, tear index $\left(13.4 \mathrm{mN} \cdot \mathrm{m}^{2} / \mathrm{g}\right)$, tensile index $(71 \mathrm{Nm} / \mathrm{g})$, Burst index (4.8 KN/g) and folding endurance (82) recommend the cellulosic pulp from Sugarcane Bagasse obtained from the MEA process for strengthening the virgin fiber in recycled papers and also for developing certain types of printing and packaging papers. Due to the awareness towards the negative impact of kraft mill's effluent to the environment recently, soda pulping started to regain its popularity among the pulp mills especially non-wood based pulp mills. MEA process is more economically attractive given its high pulp yield, despite the significant increase in chemical demand for bleaching. MEA pulping is a good alternative to soda pulping furnishing high pulp yield with less cooking temperature, i.e. $150^{\circ} \mathrm{C}$, thereby saving a considerable amount of energy with less odoriferous pollutants and pollution load associated with the soda process.
\end{abstract}

Keywords: Soda; Monoethanolamine (M.E.A.); Pulp Screen Yield; Kraft; Sugarcane Bagasse; Paper

\footnotetext{
${ }^{*}$ Corresponding author: Henry Okwudili Chibudike

Chemical, Fiber and Environmental Technology Department, Federal Institute of Industrial Research, Oshodi, F.I.I.R.O., LagosNigeria.

Copyright $(2021$ Author(s) retain the copyright of this article. This article is published under the terms of the Creative Commons Attribution Liscense 4.0.
} 


\section{Introduction}

The pulp and paper industry is one of the most polluting industries in the world facing social pressure related to its environmental and sustaining efficiency leading to technological evolutions. The emissions from pulp and paper mills either by air or water gives a serious impact on environmental quality that eventually affects the health of both human and ecosystems. The effluents usually generated from various stages of pulping and bleaching process are often discharged into the downstream. These effluents contains compounds such as resin acids, unsaturated acids, chlorinated phenolic, chlorinated dioxins and furans which are toxic to human bodies and aquatic life. In addition, the major air pollutants include fine and coarse particulates, sulfur dioxide, nitrogen oxides, volatile organic compounds (VOCs) from the black liquor oxidation process and reduced sulfur gases which emits unpleasant odor [1].

kraft pulping is the most dominant pulping process in the world of pulp and paper production and the dominance of this process is anchored upon its versatility to pulp almost any type of wood successfully, but prominent are the emission of some fowl smelling malodorous pollutant. Kraft pulping is always associated with severe environment pollution especially the air pollution. The air pollution from the kraft pulping is a major concern with the emission of sulphur gases into the atmosphere with a rate of 0.3-3 kilograms per metric tonne $(\mathrm{kg} / \mathrm{t}$ ) of air-dried pulp (ADP) (World Bank Group, 1998). The four reduced sulphur gases are hydrogen sulfide, methyl mercaptan, dimethyl sulfide and dimethyl disulfide. Obnoxious gaseous odor are released even from the advanced kraft mills. All the gases have extreme low odor thresholds, which indicated that long term exposure to these gases, the balance of ecosystem and even human health will be seriously interfered $[2,3]$.

Due to environmental concerns, the kraft (dominating pulping) process has to be modified or substituted by a less polluting process. The substituted process must give good pulp yield and quality, yet compatible with the existing kraft process equipment and operations. One of the pulping processes that may be a good alternative to the kraft process is the soda process (Holton, 1977). Soda pulping is the dominant process for annual plants, but it is faced with severe drawbacks. Strongly alkaline cooking liquors dissolve carbohydrates to a great extent with negative impact on pulp yield. Most annual plants have a high content of silica, which is dissolved to a high extent in the strongly alkaline cooking liquor and thus creates serious problems in the evaporators, the recovery boilers and in the causticizing plant. These are the main reasons why soda pulping black liquor handling and recovery of chemicals is still problematic [5, 6 and 7$]$.

Delignification by use of monoethanolamine (MEA) is an innovative, environmentally friendly chemical pulping process that works without the use of sulphur compounds, with a particular benefit of simple MEA recovery by distillation, allowing black liquor combustion to be dispensed and the dissolved lignin recovered. Apart from high selectivity of MEA which results in pulps with high yields, low kappa numbers and acceptable strength properties, the most important advantage of MEA pulping of annual plants is the direct MEA recovery by distillation. Monoethanolamine (MEA) has several advantages when compared to other popular methods such as kraft or sulfite pulping. In particular, the ability to obtain relatively high quality lignin adds value to a process stream otherwise considered as waste. Organic solvents are easily recovered by distillation, leading to less water pollution and elimination of the odor usually associated with Soda and kraft pulping. The objective of this research work was to develop an eco-friendly and energy saving biomaterials and processes that would lead to implementation of sustainable manufacturing strategies.

\section{Experimental}

\subsection{Materials}

In this research work, Nigeria-grown Agro-based Fibers (Sugarcane Bagasse) generated during post- harvest treatment of Sugarcane at a plantation in Minna, Niger State, Nigeria were used.

\subsection{Production of Pulp from MEA and Soda Processes: Working plan}

Figure 1 depicts the working plan. The agro-biomass was converted into brown pulp of two (2) different delignification degrees from two (2) different processes, kappa no. ranging from 12.7 to 16.9 from MEA Process and kappa no. ranging from 13.5 to 22.4 from soda Process. The resulting pulps were fully bleached by the D1-Ep-D2 sequence and characterized for their beatability, drainability and physical-mechanical properties. 


\subsection{Outline of the Production Process}

Figure 1 illustrates the process of making paper from Agro-biomass. The Agro-wastes (sugarcane bagasse) was converted into brown pulp at a delignification degree of 18.2 kappa from MEA Process. The resulting pulps were fully bleached by the D1-Ep-D2 sequence and characterized for their beatability, drainability and physical-mechanical properties.

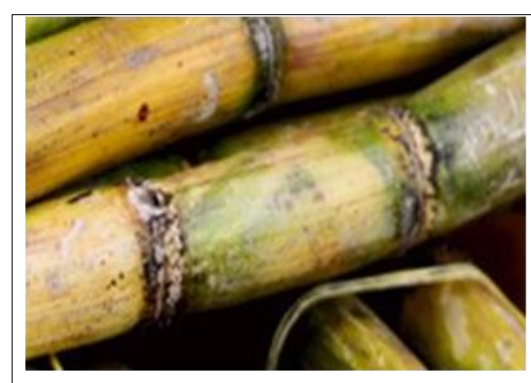

Freshly Harvested Sugarcane

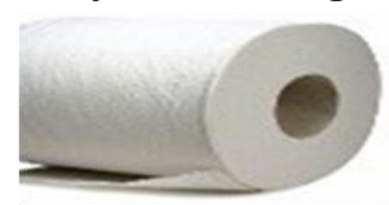

OPERATION

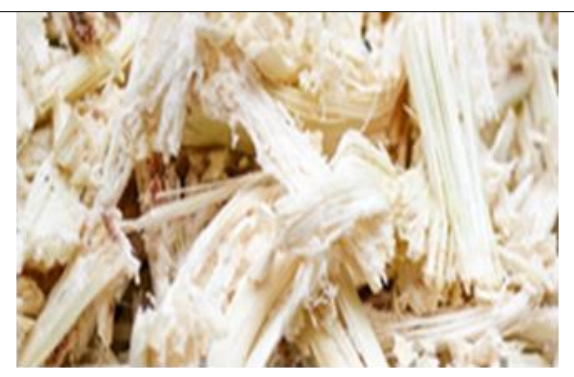

Sugar-cane Bagasse (Usually discarded... after extraction ready for pulping operation

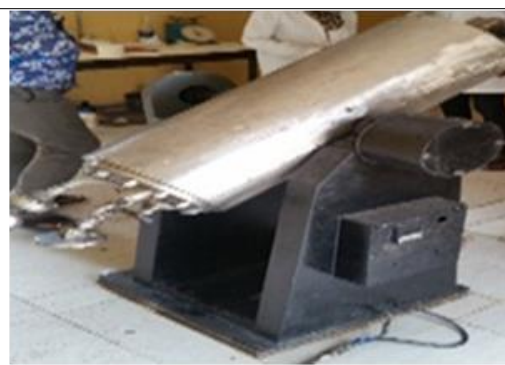

PULPING OPERATION<smiles>[CH]1C=C1</smiles>

BEATING

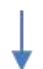

PAPER MAKING SCREENING

Figure 1 Steps in Agro-biomass Sugarcane (Bagasse) fractionation and conversion to paper

\subsection{Experimental design for the pulping conditions}

The pulping experimental design considered the following factors are described in table 1

Table 1 Experimental Design for both Processes

\begin{tabular}{|l|c|c|c|c|c|c|}
\hline \multirow{2}{*}{$\begin{array}{l}\text { Experimental } \\
\text { Conditions }\end{array}$} & \multicolumn{2}{|c|}{ Monoethanolamine (MEA) Process } & \multicolumn{3}{c|}{ Soda (NaOH) Process } \\
\cline { 2 - 7 } & $\begin{array}{c}\text { MEA } \\
\text { Charge (\%) }\end{array}$ & $\begin{array}{c}\text { Maximum } \\
\text { Temp. ( }\end{array}$ & $\begin{array}{c}\text { Maximum } \\
\text { Cooking } \\
\text { Duration } \\
\text { (minutes) }\end{array}$ & $\begin{array}{c}\text { Soda } \\
\text { Charge } \\
\text { (\%) }\end{array}$ & $\begin{array}{c}\text { Maximum } \\
\text { Temp. ( }\end{array}$ & $\begin{array}{c}\text { Maximum } \\
\text { Cooking } \\
\text { Duration } \\
\text { (minutes) }\end{array}$ \\
\hline Factor 1 & 50 & 150 & 60 & 10 & 150 & 60 \\
\hline Factor 2 & 75 & 160 & 90 & 15 & 160 & 90 \\
\hline Factor 3 & 100 & 170 & 120 & 20 & 170 & 120 \\
\hline
\end{tabular}

Table 2 Description of both pulping [Monoethanolamine (MEA) and the Soda ( $\mathrm{NaOH})$ ] processes

\section{Monoethanolamine (MEA) pulping}

After a thorough cleaning process, $2 \mathrm{~kg}$ of air-dry sample was loaded into a $15 \mathrm{~L}$ capacity batch reactor (digester) with eight (8) liter cooking liquor at liquor-sample ratio of 4:1. The digester is furnished with an outer electrical heating jacket. The lid of the digester was firmly bolted to prevent leakage, the digester was switched on and the time of rise of temperature and pressure was noted at intervals of five (5) minutes. The content of the digester was stirred while in operation by rotating the vessel via a motor connected through a rotary axle to a control unit, including measurement and control instruments of pressure and temperature, to facilitate attainment of the working temperature $\left(5^{\circ} \mathrm{C} / \mathrm{min}\right)$. The pulping temperatures gradually rose and allowed to be steady at varying maximum temperatures of 150,160 and $170^{\circ} \mathrm{C}$. The digester was switched off after varying maximum cooking periods of 60,90 
and 120 minutes from start of operation and allowed to cool below 60oC before the content were blown down. The digester's initial temperature, pressure and starting time were all noted, and the various changes in these parameters were also recorded. The resultant pulp was subjected to thorough washing with plenty of water. When it was observed that subsequent washing resulted in no further change in color, the pulp was transferred into the valley beater for processing into a more refined pulp.

\section{Soda pulping}

After a thorough cleaning process, $2 \mathrm{~kg}$ of air-dry sample was loaded into a $15 \mathrm{~L}$ capacity batch reactor (digester) with eight (8) liter cooking liquor at liquor-sample ratio of 4:1. The soda pulping was carried out using the batch reactor (digester). It's working principle was carried out as applied in the MEA process, aiming at producing pulps based on the following parameters: ratio of liquor/biomass 4 to 1, maximum temperatures 150,160 and $170^{\circ} \mathrm{C}$ and maximum cooking duration of 60,90 and 120 minutes from start of operation. The pulping temperatures gradually rose and allowed to attain the various operational conditions stated above. The digester's initial temperature, pressure and starting time were all noted, and the various changes in these parameters were also recorded. The resultant pulp was subjected to thorough washing with plenty of water. When it was observed that subsequent washing resulted in no further change in color, the pulp was transferred into the valley beater for processing into a more refined pulp.

\subsection{Beating Process}

The beating process was conducted using the valley beater at 1000 and 8000 beating revolutions. The beating revolution was chosen based on the previous study from 1000 to 24000 beating revolution. It showed that after 8000 to 24000 beating revolution, there was no significant increasing of paper mechanical properties with the increasing of the beating revolution. That is the justification of this study for using 1000 beating as the basic beating process and 8000 as the optimum beating for achieving highest paper properties.

\subsection{Totally Chlorine Free (TCF) Bleaching}

The pulps resulting from the MEA and Soda pulping processes were fully bleached by a totally chlorine-free sequence performed in three stages to kappa number ranging from 12.7 to 16.9 and 13.5 to 22.4 respectively. Using a combination of $70 \%$ hydrogen peroxide and dilute sodium hydroxide at varying stoichiometric ratios in three (3) different stages at varying temperatures and reaction time. This sequence is represented in a shorthand form as D1-Ep-D2.

Table 3 Conditions of the Bleaching Process

\begin{tabular}{|c|c|c|c|}
\hline Stage & D1 & Ep & D2 \\
\hline \multirow[t]{2}{*}{ Chemical charge } & $\begin{array}{ll}\text { Hydrogen } & \text { Peroxide } \\
\left(\mathrm{H}_{2} \mathrm{O}_{2}\right) & \end{array}$ & Hydrogen Peroxide $\left(\mathrm{H}_{2} \mathrm{O}_{2}\right)$ & Hydrogen Peroxide $\left(\mathrm{H}_{2} \mathrm{O}_{2}\right)$ \\
\hline & - & $\mathrm{NaOH}(1.5 \%)$ & - \\
\hline Pulp consistency & $10 \%$ & $10 \%$ & $10 \%$ \\
\hline Temperature & $70^{\circ} \mathrm{C}$ & - & $70^{\circ} \mathrm{C}$ \\
\hline Time & 15 minutes & 8 minutes & 12 minutes \\
\hline
\end{tabular}

\subsection{Screening of Agro-biomass (Sugarcane Bagasse)}

The pulp was passed through a screening process. Cooked sample chips were put through the screening machine. Only acceptable size of the sample fiber passed through the screen plate and the rejected or oversized fiber were left on the screen plate. This process is crucial in papermaking to ensure smooth and uniform paper texture. Pulp yield was determined in accordance with TAPPI standards T-257. 
Table 4 Optimum Experimental Pulping Conditions of MEA \& the Soda Process

\begin{tabular}{|l|c|c|}
\hline \multirow{2}{*}{ Parameters } & \multicolumn{2}{|c|}{$\begin{array}{c}\text { Optimum Parameters (Best Conditions of Cooking } \\
\text { Operation showing Values of Independent Variables) }\end{array}$} \\
\cline { 2 - 3 } & MEA Pulping & Soda Pulping \\
\hline Air dry weight of Bagasse (kg) (A.D) & 2 & 2 \\
\hline Ratio of liquor/biomass & $4: 1$ & $4: 1$ \\
\hline Maximum temperature (degree Celsius) & $150,160,170$ & $150,160,170$ \\
\hline Time to reach maximum temperature (minutes) & $43,55,67$ & $36,47,56$ \\
\hline Time at maximum temperature (minutes) & $17,35,53$, & $24,43,64$ \\
\hline Liquor charge (\%) & $50,75,100$ & $10,15,20$ \\
\hline Over-all cooking time (minutes) & $60,90,120$ & 60.90 .120 \\
\hline Blow-down temperature (degree Celsius) & 60 & 60 \\
\hline
\end{tabular}

\section{Results and discussion}

Table 5 Experimental Conditions used in the MEA Pulping applied to the agro-based fiber (Sugarcane Bagasse) investigated, showing values of cooking/Independent and dependent variables for pulp properties.

\begin{tabular}{|c|c|c|c|c|c|c|c|c|}
\hline \multirow[t]{2}{*}{ Experiment } & \multicolumn{3}{|c|}{ Independent Variables } & \multicolumn{5}{|c|}{ Dependent Variables } \\
\hline & $\begin{array}{c}\text { Cooking } \\
\text { Temp. (Degree } \\
\text { Celsius) } \\
\end{array}$ & $\begin{array}{c}\text { Cooking } \\
\text { Time } \\
\text { (minutes) }\end{array}$ & $\begin{array}{c}\text { MEA \% } \\
\text { (D.W.) }\end{array}$ & TY (\%) & $\begin{array}{c}\text { SY } \\
(\%)\end{array}$ & $\begin{array}{c}\text { Rejects } \\
\text { (\%) }\end{array}$ & $\begin{array}{c}\text { Kappa } \\
\text { No. }\end{array}$ & $\begin{array}{c}\text { Viscosity } \\
\mathrm{ml} / \mathrm{g}\end{array}$ \\
\hline 1 & 150 & 60 & 50 & 39.51 & 36.24 & 3.27 & 54.64 & 470 \\
\hline 2 & 150 & 90 & 75 & 49.09 & 47.23 & 1.86 & 36.28 & 650 \\
\hline 3 & 150 & 120 & 100 & 52.99 & 48.46 & 4.53 & 20.01 & 400 \\
\hline 4 & 160 & 60 & 50 & 41.31 & 37.98 & 3.33 & 69.30 & 518 \\
\hline 5 & 160 & 90 & 75 & 53.60 & 51.02 & 2.58 & 23.45 & 630 \\
\hline 6 & 160 & 120 & 100 & 55.56 & 52.00 & 3.56 & 19.87 & 480 \\
\hline 7 & 170 & 60 & 50 & 39.08 & 38.65 & 0.33 & 76.09 & 490 \\
\hline 8 & 170 & 90 & 75 & 54.72 & 51.48 & 3.24 & 24.02 & 500 \\
\hline 9 & 170 & 120 & 100 & 55.12 & 50.97 & 4.15 & 27.50 & 460 \\
\hline 10 & 150 & 60 & 50 & 49.49 & 48.30 & 1.19 & 37.07 & 450 \\
\hline 11 & 150 & 90 & 75 & 49.55 & 47.52 & 2.03 & 24.99 & 630 \\
\hline 12 & 150 & 120 & 100 & 53.25 & 52.70 & 0.55 & 48.11 & 425 \\
\hline 13 & 160 & 60 & 50 & 53.33 & 51.14 & 1.19 & 17.98 & 450 \\
\hline 14 & 160 & 90 & 75 & 47.53 & 45.74 & 1.79 & 24.03 & 580 \\
\hline 15 & 160 & 120 & 100 & 52.01 & 50.55 & 1.46 & 47.04 & 480 \\
\hline 16 & 170 & 60 & 50 & 53.04 & 50.68 & 2.36 & 17.77 & 465 \\
\hline 17 & 170 & 90 & 75 & 51.61 & 41.89 & 9.72 & 23.49 & 560 \\
\hline 18 & 170 & 120 & 100 & 51.14 & 49.01 & 2.13 & 45.97 & 530 \\
\hline 19 & 150 & 60 & 50 & 44.40 & 43.89 & 0.51 & 39.67 & 609 \\
\hline 20 & 150 & 90 & 75 & 54.73 & 53.27 & 1.46 & 16.20 & 435 \\
\hline 21 & 150 & 120 & 100 & 49.59 & 42.16 & 7.43 & 43.99 & 535 \\
\hline
\end{tabular}




\begin{tabular}{|l|c|c|c|c|c|c|c|c|}
\hline 22 & 160 & 60 & 50 & 49.01 & 44.49 & 4.52 & 51.40 & 818 \\
\hline 23 & 160 & 90 & 75 & 52.73 & 52.27 & 0.46 & 19.02 & 470 \\
\hline 24 & 160 & 120 & 100 & 50.22 & 41.21 & 11.01 & 49.08 & 525 \\
\hline 25 & 170 & 60 & 50 & 49.56 & 46.12 & 3.44 & 57.58 & 420 \\
\hline 26 & 170 & 90 & 75 & 54.44 & 52.94 & 1.50 & 17.20 & 510 \\
\hline 27 & 170 & 120 & 100 & 52.45 & 43.74 & 8.71 & 46.06 & 505 \\
\hline
\end{tabular}

$\mathrm{TY}=$ Total yield, $\mathrm{SY}=$ Screen yield

Table 6 Experimental Conditions used in the Soda Pulping applied to the agro-based fiber (Sugarcane Bagasse) investigated, showing values of cooking/Independent and dependent variables for pulp properties

\begin{tabular}{|c|c|c|c|c|c|c|c|c|}
\hline \multirow{2}{*}{$\begin{array}{c}\text { Experimen } \\
t\end{array}$} & \multicolumn{3}{|c|}{ Independent Variables } & \multicolumn{5}{|c|}{ Dependent Variables } \\
\hline & $\begin{array}{c}\text { Cooking } \\
\text { Temp. } \\
\text { (degree } \\
\text { Celsius) }\end{array}$ & $\begin{array}{c}\text { Cooking } \\
\text { Time } \\
\text { (minutess) }\end{array}$ & $\begin{array}{c}\mathrm{NaOH} \\
\text { (\%) } \\
\text { (D.W.) }\end{array}$ & $\begin{array}{l}\text { TY } \\
(\%)\end{array}$ & $\begin{array}{l}\text { SY } \\
(\%)\end{array}$ & $\begin{array}{l}\text { Reject } \\
\text { s (\%) }\end{array}$ & $\begin{array}{c}\text { Kappa } \\
\text { No. }\end{array}$ & $\begin{array}{l}\text { Viscosit } \\
\text { y mL/g }\end{array}$ \\
\hline 1 & 150 & 60 & 10 & 44.51 & 44.24 & 0.27 & 19.64 & 360 \\
\hline 2 & 150 & 90 & 15 & 49.09 & 43.23 & 5.86 & 36.28 & 530 \\
\hline 3 & 150 & 120 & 20 & 53.99 & 37.46 & 16.53 & 70.01 & 310 \\
\hline 4 & 160 & 60 & 10 & 44.31 & 33.98 & 10.33 & 19.30 & 428 \\
\hline 5 & 160 & 90 & 15 & 49.60 & 47.90 & 1.70 & 17.50 & 440 \\
\hline 6 & 160 & 120 & 20 & 42.56 & 32.00 & 10.56 & 54.87 & 390 \\
\hline 7 & 170 & 60 & 10 & 42.08 & 41.65 & 0.43 & 20.09 & 400 \\
\hline 8 & 170 & 90 & 15 & 46.72 & 44.48 & 2.24 & 24.02 & 410 \\
\hline 9 & 170 & 120 & 20 & 52.12 & 40.97 & 11.15 & 34.50 & 370 \\
\hline 10 & 150 & 60 & 20 & 42.49 & 37.30 & 5.19 & 27.07 & 460 \\
\hline 11 & 150 & 90 & 10 & 47.55 & 45.52 & 2.03 & 24.99 & 540 \\
\hline 12 & 150 & 120 & 15 & 42.25 & 36.70 & 5.55 & 48.11 & 335 \\
\hline 13 & 160 & 60 & 20 & 44.33 & 44.14 & 0.19 & 17.98 & 340 \\
\hline 14 & 160 & 90 & 10 & 47.53 & 45.74 & 1.79 & 24.03 & 450 \\
\hline 15 & 160 & 120 & 15 & 51.01 & 46.55 & 4.46 & 27.04 & 390 \\
\hline 16 & 170 & 60 & 20 & 55.04 & 44.68 & 10.36 & 17.77 & 375 \\
\hline 17 & 170 & 90 & 10 & 47.61 & 45.89 & 1.72 & 23.49 & 470 \\
\hline 18 & 170 & 120 & 15 & 51.14 & 44.01 & 7.13 & 25.97 & 450 \\
\hline 19 & 150 & 60 & 15 & 44.40 & 43.89 & 0.51 & 17.67 & 519 \\
\hline 20 & 150 & 90 & 20 & 47.32 & 45.59 & 1.73 & 22.09 & 345 \\
\hline 21 & 150 & 120 & 10 & 41.59 & 32.16 & 9.43 & 43.99 & 445 \\
\hline 22 & 160 & 60 & 15 & 45.01 & 44.49 & 0.52 & 17.40 & 708 \\
\hline 23 & 160 & 90 & 20 & 46.73 & 45.27 & 1.46 & 21.02 & 380 \\
\hline 24 & 160 & 120 & 10 & 42.22 & 38.21 & 14.01 & 49.08 & 435 \\
\hline 25 & 170 & 60 & 15 & 44.56 & 44.12 & 0.44 & 17.58 & 330 \\
\hline 26 & 170 & 90 & 20 & 47.44 & 45.94 & 1.50 & 23.16 & 420 \\
\hline 27 & 170 & 120 & 10 & 42.45 & 33.74 & 8.71 & 46.06 & 415 \\
\hline
\end{tabular}


Table 7 Lack of Fit Tests analyzed for the Monoethanolamine Process

\begin{tabular}{|l|c|c|c|c|c|l|}
\hline \multicolumn{1}{|c|}{ Source } & Sum of Squares & DF & Mean Square & F Value & Prob $>$ F & \\
\hline Linear & 55.86 & 11 & 5.08 & 0.39 & 0.9088 & Suggested \\
\hline 2FI & 47.33 & 8 & 5.92 & 0.46 & 0.8443 & \\
\hline Quadratic & 38.77 & 5 & 7.75 & 0.60 & 0.7059 & \\
\hline Cubic & 0.000 & 0 & & & & Aliased \\
\hline Pure Error & 64.66 & 5 & 12.93 & & & \\
\hline
\end{tabular}

Table 8 Model Summary Statistics analyzed for the Monoethanolamine Process

\begin{tabular}{|l|c|c|c|c|c|c|}
\hline Source & Std. Dev & R-Squared & Adjusted R-Squared & Predicted R-Squared & PRESS & \\
\hline Linear & 2.74 & 0.2360 & 0.0928 & -0.1768 & 185.64 & Suggested \\
\hline 2FI & 2.94 & 0.2901 & -0.0376 & -1.0153 & 317.92 & \\
\hline Quadratic & 3.22 & 0.3444 & -0.2457 & -3.9424 & 779.67 & \\
\hline
\end{tabular}

"Lack of Fit Tests": Want the selected model to have insignificant lack-of-fit. Values of "Prob > F" less than 0.0500 indicate model terms are significant. In this case there are no significant model terms. Values greater than 0.1000 indicate the model terms are not significant. If there are many insignificant model terms (not counting those

required to support hierarchy), model reduction may improve the model. The "Lack of Fit F-value" of 0.51 implies the Lack of Fit is not significant relative to the pure error. Non-significant lack of fit is good because it is desired that the model should fit.

Table 9 ANOVA for Response Surface Mean Model analyzed for the Monoethanolamine Process [Partial sum of squares]

\begin{tabular}{|l|c|c|c|c|c|}
\hline Source & Sum of Squares & DF & Mean Square & F Value & Prob > F \\
\hline Model & 0.000 & 0 & & & \\
\hline Residual & 157.75 & 19 & 8.30 & & \\
\hline Lack of Fit & 93.09 & 14 & 6.65 & 0.51 & 0.8498 \\
\hline Pure Error & 64.66 & 5 & 12.93 & & \\
\hline Cor Total & 157.75 & 19 & & & \\
\hline
\end{tabular}

Table 10 Sequential Model Sum of Squares analyzed for the Soda Process

\begin{tabular}{|l|c|c|c|c|c|l|}
\hline Source & Sum of Squares & DF & Mean Square & F Value & Prob $>$ F & \\
\hline Mean & 39295.00 & 1 & 39295.00 & & & Suggested \\
\hline Linear & 5.61 & 3 & 1.87 & 0.37 & 0.7751 & \\
\hline 2FI & 1.01 & 3 & 0.34 & 0.055 & 0.9822 & \\
\hline Quadratic & 34.95 & 3 & 11.65 & 2.61 & 0.1096 & Suggested \\
\hline Cubic & 25.81 & 7 & 3.69 & 0.59 & 0.7481 & Aliased \\
\hline Residual & 18.88 & 3 & 6.29 & & & \\
\hline Total & 39381.26 & 20 & 1969.06 & & & \\
\hline
\end{tabular}


Table 11 Model Summary Statistics analyzed for the Soda Process

\begin{tabular}{|l|c|c|c|c|c|l|}
\hline Source & Std. Dev. & R-Squared & Adjusted R-Squared & Predicted R-Squared & PRESS & \\
\hline Linear & 2.25 & 0.0650 & -0.1103 & -0.5391 & 132.77 & \\
\hline 2FI & 2.48 & 0.0768 & -0.3493 & -2.1783 & 274.18 & \\
\hline Quadratic & 2.11 & 0.4819 & 0.0157 & -1.7050 & 233.35 & Suggested \\
\hline Cubic & 2.51 & 0.7811 & -0.3863 & -19.3504 & 1755.53 & Aliased \\
\hline
\end{tabular}

Table 12 ANOVA for Response Surface Quadratic Model analyzed for the Soda Process [Partial sum of squares]

\begin{tabular}{|l|c|c|c|c|c|l|}
\hline Source & Sum of Squares & DF & Mean Square & F Value & Prob $>$ F & \\
\hline Model & 41.57 & 9 & 4.62 & 1.03 & 0.4756 & not significant \\
\hline $\mathrm{A}$ & 0.41 & 1 & 0.41 & 0.092 & 0.7675 & \\
\hline $\mathrm{B}$ & 6.97 & 1 & 6.97 & 1.56 & 0.2401 & \\
\hline $\mathrm{C}$ & 1.68 & 1 & 1.68 & 0.38 & 0.5533 & \\
\hline $\mathrm{A}^{2}$ & 3.50 & 1 & 3.50 & 0.78 & 0.3971 & \\
\hline $\mathrm{B}^{2}$ & 29.99 & 1 & 29.99 & 6.71 & 0.0269 & \\
\hline $\mathrm{C}^{2}$ & 6.85 & 1 & 6.85 & 1.53 & 0.2441 & \\
\hline $\mathrm{AB}$ & 0.21 & 1 & 0.21 & 0.046 & 0.8340 & \\
\hline $\mathrm{AC}$ & 0.85 & 1 & 0.85 & 0.19 & 0.6720 & \\
\hline $\mathrm{BC}$ & 0.53 & 1 & 0.53 & 0.12 & 0.7365 & \\
\hline Residual & 44.69 & 10 & 4.47 & & & \\
\hline Cor Total & 86.27 & 19 & & & & \\
\hline
\end{tabular}

The "Model F-value" of 1.03 implies the model is not significant. Values of "Prob > F" less than 0.0500 indicate model terms are significant. In this case B2 are significant model terms.

Values greater than 0.1000 indicate the model terms are not significant. If there are many insignificant model terms (not counting those required to support hierarchy), model reduction may improve your model.

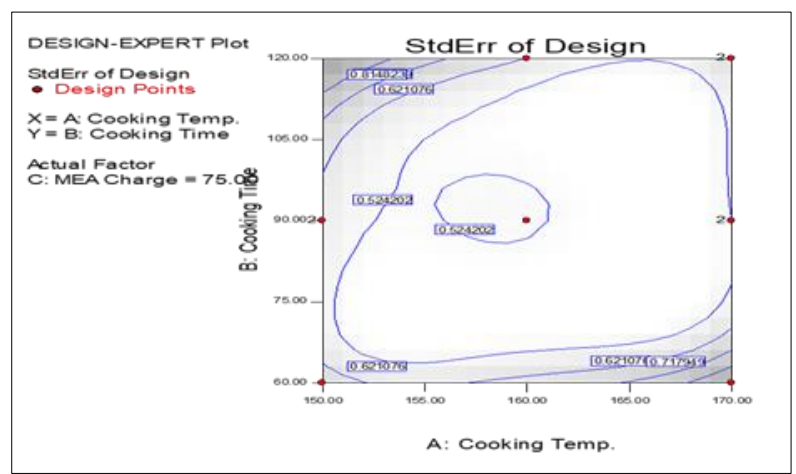

Figure 2 Standard Error of Design for the Monoethanoleamine Process

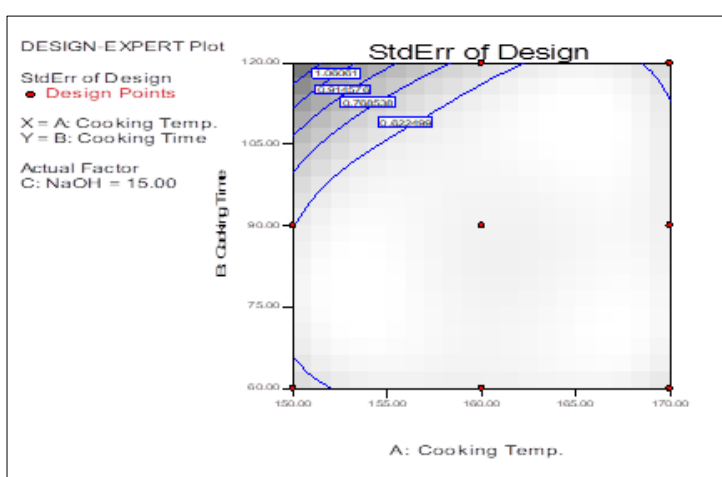

Figure 3 Standard Error of Design for the Soda Process 


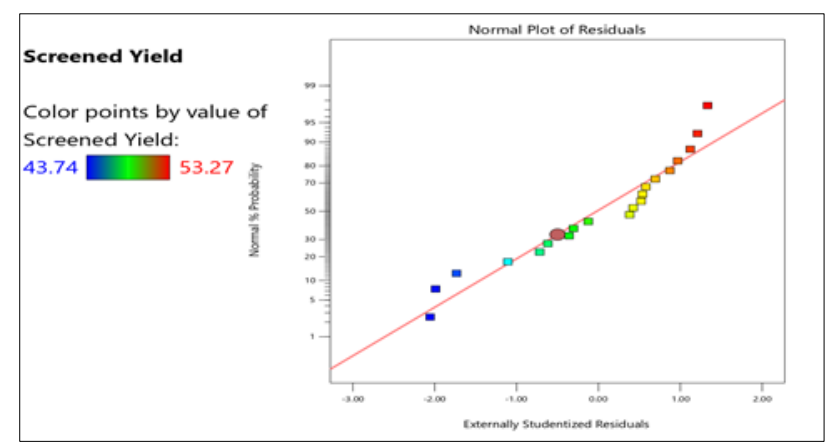

Figure 4 Diagnostic of Normal Plot of Residuals for MEA-process

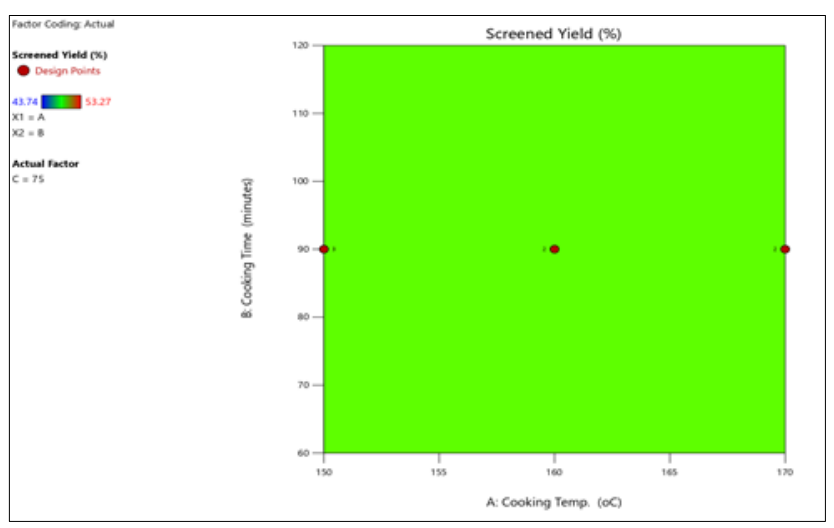

Figure 6 Model Graph of Contour of Screened Yield for MEA Process

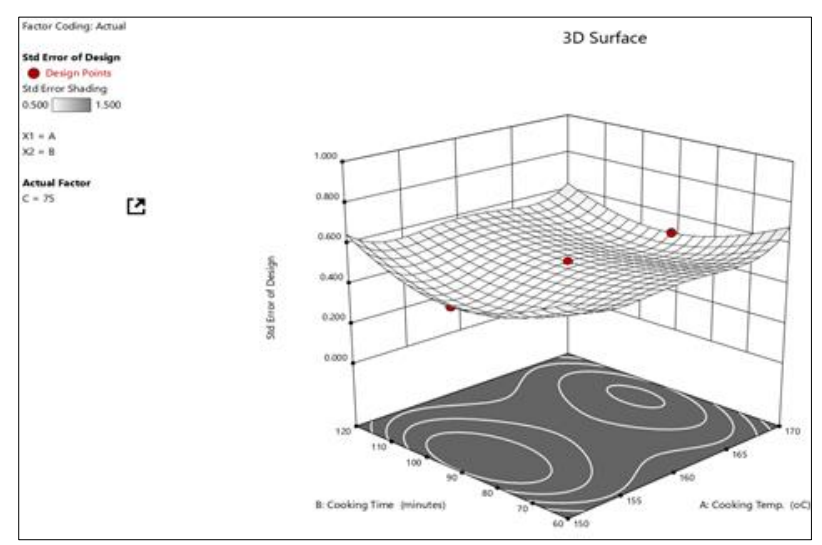

Figure 8 Desirability Plot of Numerical Optimization for MEA Process

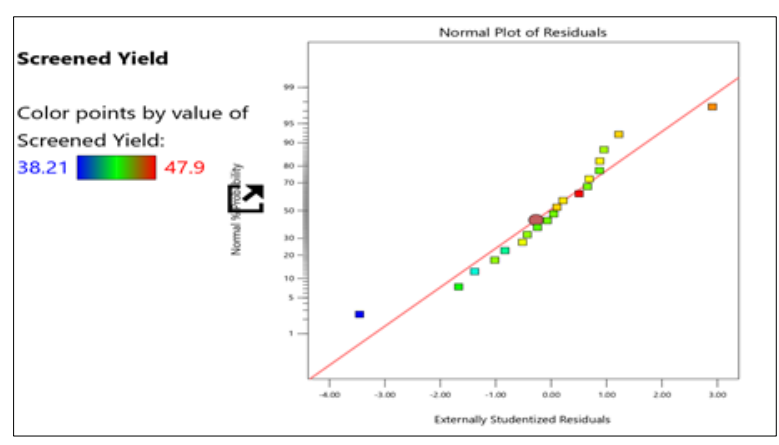

Figure 5 Diagnostic of Normal Plot of Residuals for Soda Process

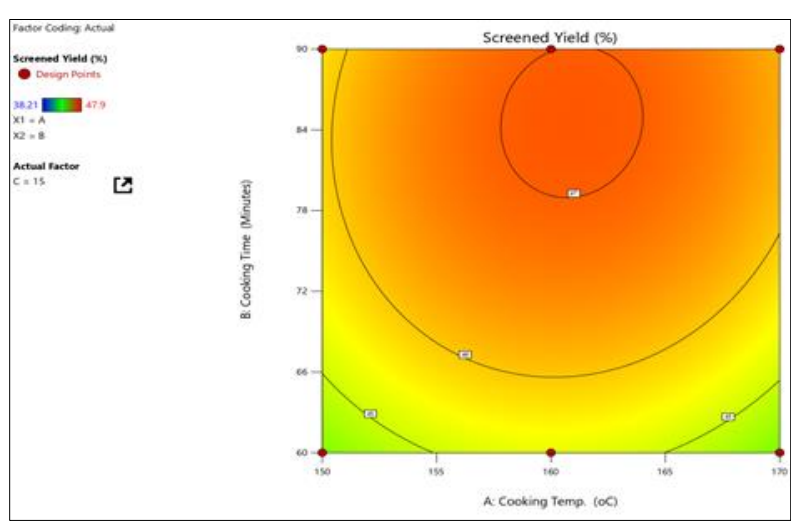

Figure 7 Model Graph of Contour of Screened Yield for Soda Process

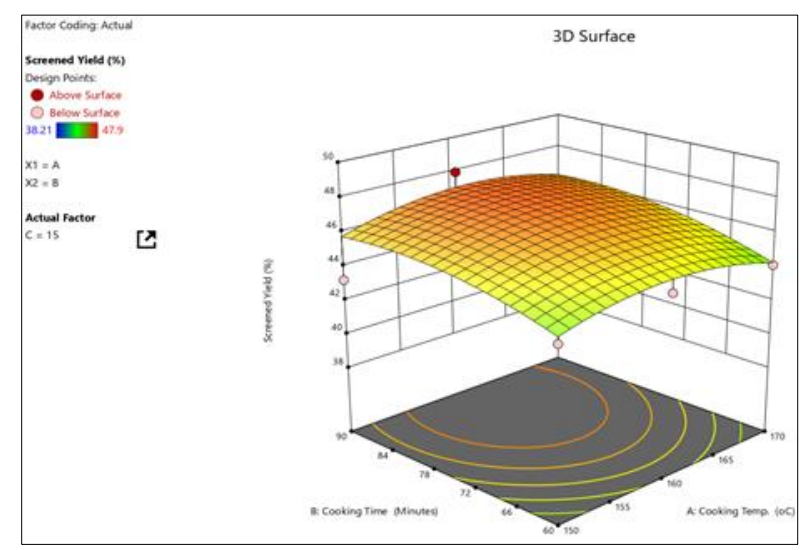

Figure 9 Desirability Plot of Numerical Optimization for Soda Process 


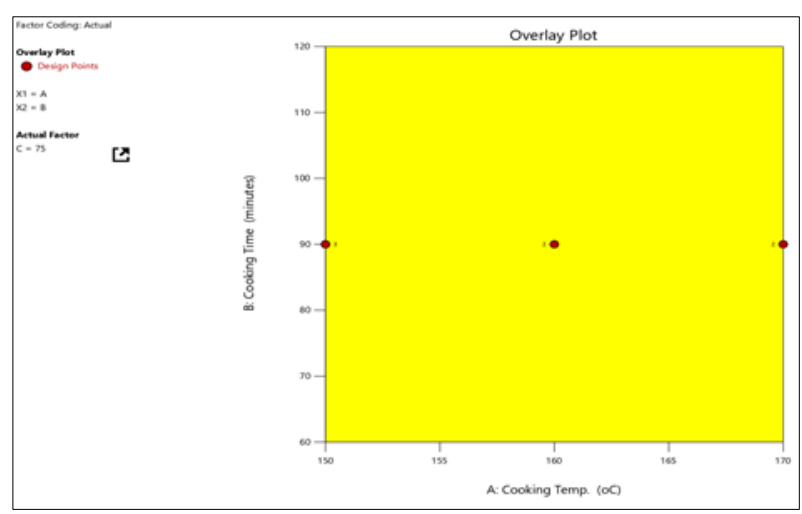

Figure 10 Overlay Plot of Graphical Optimization for MEA Process

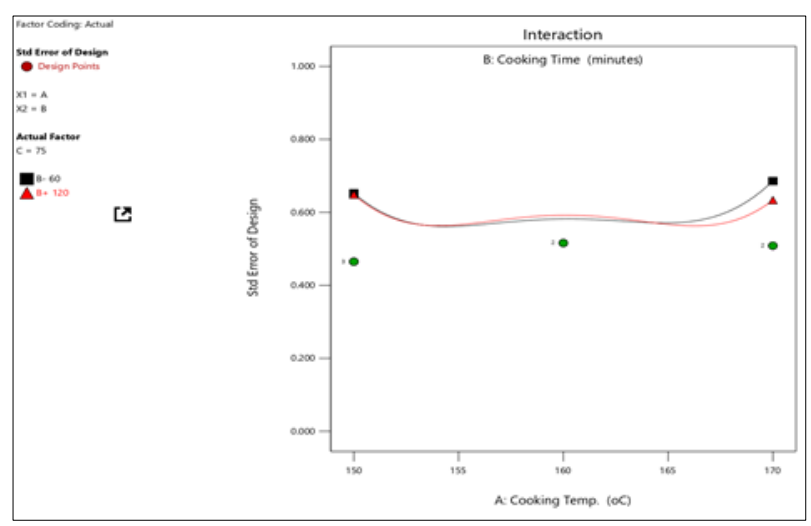

Figure 12 Plot of Multiple Interaction of Reactant for MEA Process
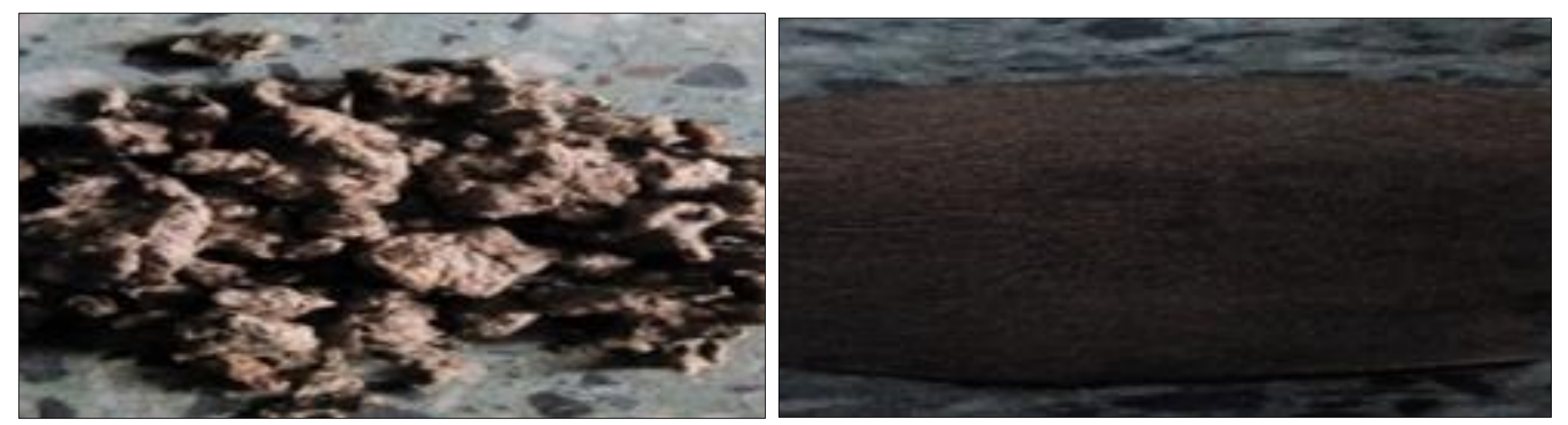

Figure 14 Unbleached EFB Pulp Samples and Pulp Sheets from MEA Process

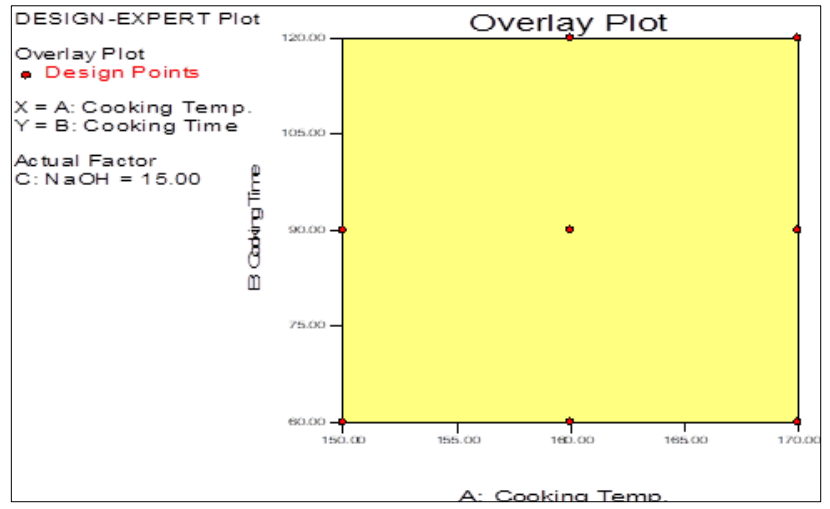

Figure 11 Overlay Plot of Graphical Optimization for Soda Process

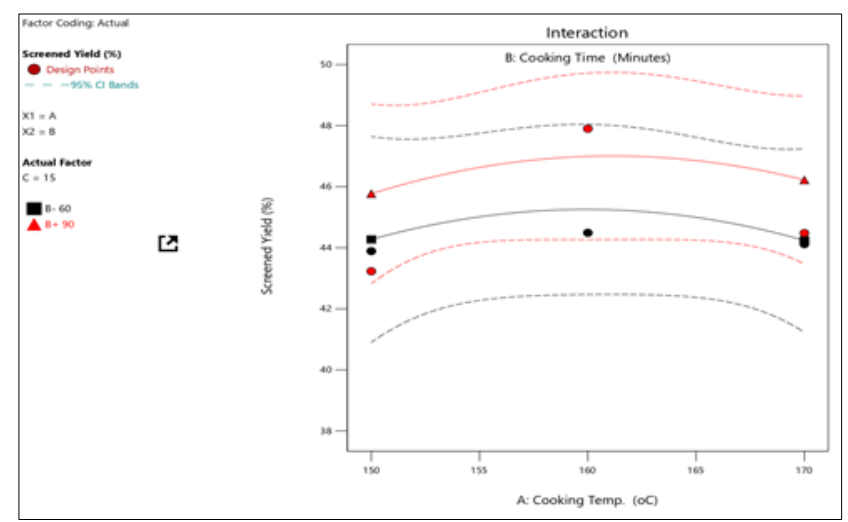

Figure 13 Plot of Multiple Interaction of Reactant for Soda Process 

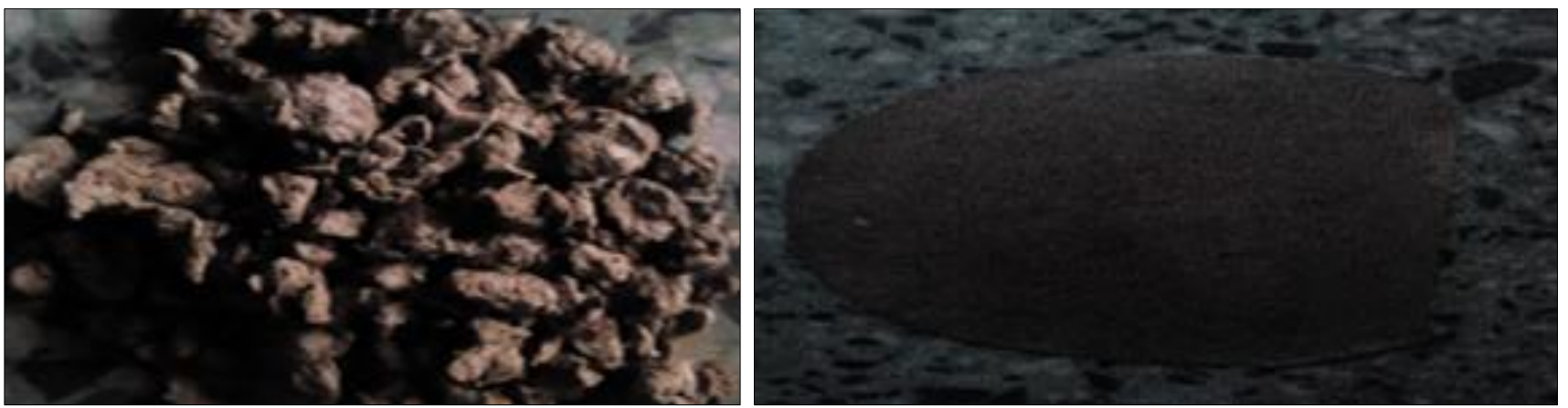

Figure 15 Unbleached EFB Pulp Samples and Pulp Sheets from Soda Process
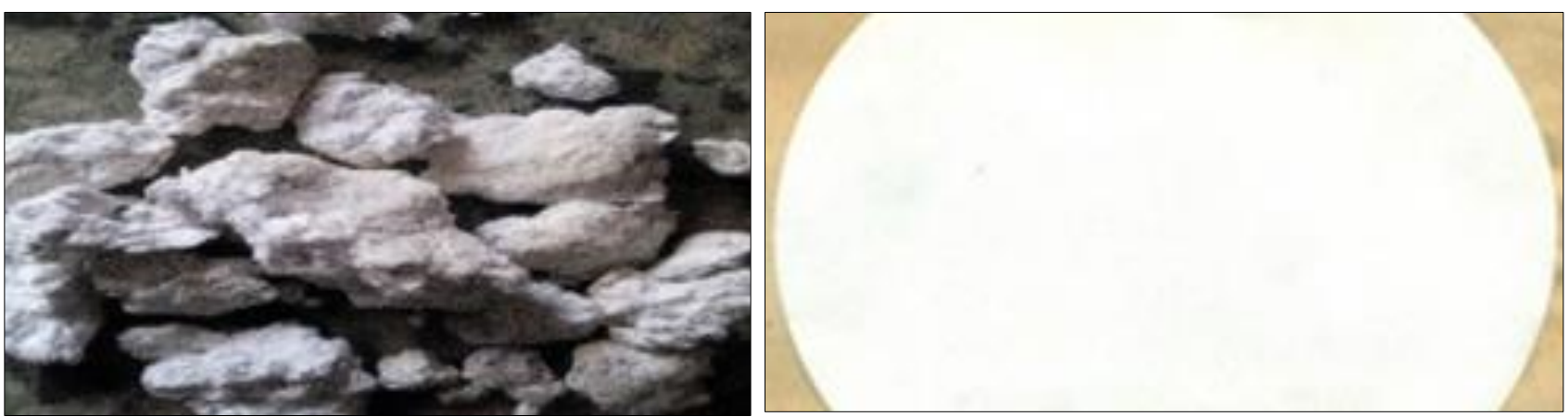

Figure 16 EFB Pulp Samples from MEA Process Bleached to 12.7 Kappa Number and Pulp sheets
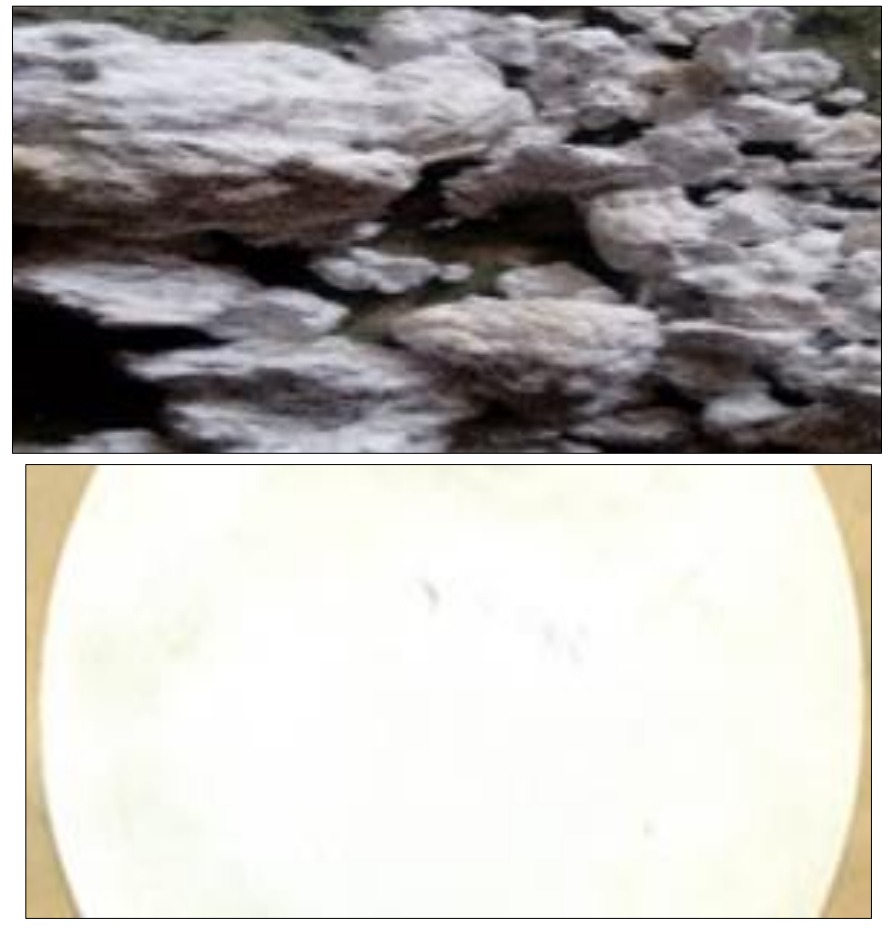

Figure 17 EFB Pulp Samples from Soda Process Bleached to 13.5 Kappa Number and Pulp Sheets

In this study pulping of sugarcane bagasse with MEA was investigated in comparison to conventional soda pulping as reference. At optimum cooking conditions of temperature $\left(150^{\circ} \mathrm{C}\right)$, cooking time (90 minutes) and with pure MEA 
(75\%), a sufficient delignification was achieved. The main focus laid on reduction of the MEA charge by partial substitution with water. A MEA/water ratio of 75/25 was successfully applied, furnishing a pulp yield of 54.73 with a screen yield of 53.27 and a reject as low as only 1.46. Under these conditions a kappa number of 12.7 was attained which means the pulp is still bleachable. When compared with results obtained for the soda process, it was observed that at a maximum cooking temperature of $160^{\circ} \mathrm{C}$, maximum cooking time of $90 \mathrm{~min}$., and with $15 \%$ soda concentration, a sufficient delignification was achieved, furnishing a pulp yield of $49.6 \%$, screened yield of $47.9 \%$, recording a reject of $1.70 \%$ and a kappa number of 13.5. Another focus of this research was laid on the reduction of temperature. Comparing the pulping potentials of these two processes, it was observed that soda pulping required more pulping energy to the advantage of the MEA which consumed less energy. MEA process furnished higher pulp yield at lower kappa number. Also, the strength properties of MEA pulps are comparable to that of soda pulps.

The pulps obtained in the MEA/water and soda cooks were selected for bleaching. ECF bleaching (DEpD) was applied. A similar brightness of $80 \%$ ISO was reached at a kappa number below 20 for both pulps. When brightness is not crucial or no bleaching is required, but a stronger pulp is desired, one can focus on obtaining a high holocellulose content and as high as possible a yield. If such a content is to be only $10 \%$ lower than optimum value, using a high Monoethanolamine concentration (75\%), a short cooking time and a low liquid/solid ratio requires employing a temperature of $150 \mathrm{oC}$ in order to obtain a yield, holocellulose content, lignin content, and kappa number of 50-55, 75-85, 10-18 and 15-20\%, respectively. If one also desires to ensure reasonable strength in the pulp and highly efficient use of the raw material, then the yield and holocellulose content should reach preset thresholds, and the lignin content and kappa number should be as low as possible. Thus, the yield and holocellulose content can only be allowed to decrease by $15 \%$ at most from their optimum value, and a moderately high MEA concentration and low liquid/solid ratio should be used to obtain a yield, holocellulose content, lignin content and kappa number of 51-56, 79-84, 14-22, and 12-20\%, respectively, with a temperature, time, and MEA concentration of $145-155^{\circ} \mathrm{C}, 60-90$ minutes, and $70-80 \%$, respectively. The pulp thus obtained is acceptably strong possessing high holocellulose content and is easily bleached (thanks to its low lignin content and kappa number); the raw material is inefficiently used (the low yield obtained is typical of chemical pulp), but the short time and small amount of raw material used result in immobilized capital savings and it has favorable effects also on reagent recovery from the wastewater.

\section{Conclusion}

Delignification by use of monoethanolamine (MEA) is an innovative, environmental friendly chemical pulping process that works without the use of sulphur compounds, with a particular benefit of simple MEA recovery by distillation, allowing black liquor combustion to be dispensed and the dissolved lignin recovered. The MEA process is suitable for pulping both hardwood and softwood. Compared with conventional processes, the MEA process has the advantage of achieving a high degree of delignification through an increase in temperature during pulping without any appreciable damage to the cellulose. MEA pulping is none polluting process compared with the soda process which is associated with heavy pollution load. MEA pulping was selected due to its environmental and economic advantages (such as little or no emission of fowl smelling malodorous gaseous pollutants - since no sulphur compounds are used, an increase in the pulp production - as lower cooking periods are needed to obtain the same pulp quality and quantity), making the implementation of this process possible in factories situated in the vicinity of agricultural areas, since it may be adapted for low productions and may be applied to any raw wood or non-wood material.

The search for local long fiber pulp material which can be easily propagated remains one of the most important key desirderatum for the eventual resuscitation of the present mom bund paper industries of Nigeria. One important way of stemming the tide of imports is to find a good substitute to fine pulp for the use of the paper companies when they eventually start producing. Besides being an innovation and new entry into the pulp map, sugarcane bagasse can become the best gift of FIIRO into the future pulp market of the tropical world. It can be concluded from these findings that comparable high strength paper can be produced from sugarcane bagasse pulp with more environmentally friendly pulping (MEA) process.

\section{Compliance with ethical standards}

\section{Acknowledgments}

The Federal Institute of Industrial Research, Oshodi, (FIIRO), Nigeria, provided Research Support and funding for this research work. A deep gratitude goes to my co-authors Dr (mrs) Adeyoju, Adetutu Olubamike, Head of Analytical Department, Federal Institute of Industrial Research, Oshodi (FIIRO), Dr. (Mrs) Nelly Acha Ndukwe, Head, Department 
of Chemical Sciences, College of Basic and Applied Sciences, Mountain Top University, Prayer City, Magoki, Ogun State, Nigeria, and Dr (mrs Chibudike Eunice Chinedum) and Mrs Obi Ify for providing valuable contributions throughout this research work.

\section{Disclosure of conflict of interest}

There is no conflict of interest in this research work. All authors were in total agreement.

\section{References}

[1] Casey JP. Pulp and Paper: chemistry and chemical technology. 1980.

[2] Chibudike HO, Mgbachiuzo E, Adeyoju OA, Kayode OF, Arowolo AB, Orekoya EO, Tojola OB, Ojo BI. Studies of Fiber Characteristics and Paper-making Potentials of Agricultural Wastes, Nigerian Journal of Engineering Management (NJEM). 2011; 12(1): 8-11.

[3] Chibudike HO, Udohitinah JS. Local Sourcing of Non-wood Pulp Plants for Paper-making, Journal of. Chem. Soc. of Nigeria (JCSN). 2009; 34(1): 169-172.

[4] Chibudike HO, Udohitinah JS. Evaluation of Pulp and Paper-making Potentials of Cereal Straws (Agro-wastes), Journal of Engineering Research (JER). 2009; 14(4): 31-36.

[5] Holton JK. Building Technology Publications: Supplement 2. NBSIR 77-1272. 1977.

[6] Sjöström E. Wood Chemistry: Fundamentals and Applications Gulf Professional Publishing, - Nature - 2nd Ed. 1993; 293.

[7] Smook GA, Kocurek MJ. Joint Textbook Committee of the Paper Industry, Technical Association of the Pulp and Paper Industry, Canadian Pulp and Paper Association. 1992.

[8] The World Bank Group. Pollution prevention and abatement handbook: toward cleaner production, in collaboration with the United Nations Environment Programme and the United Nations Industrial Development Organization. p. cm. Washington, D.C. 1988. 